\title{
Ninhos Vazios e Pássaros Desnorteados
}

\author{
Empty Nest and Bewildered Birds \\ Vítor Portela Cardoso, Interno de Medicina Geral e Familiar na Unidade de Saúde Familiar Gualtar \\ Mestrado Integrado em Medicina pela Escola de Ciências da Saúde da Universidade do Minho
}

\section{Pontos-chave:}

Os ciclos de vida familiar respeitam uma sequência previsível de transformações, podendo a transição desencadear crises mais ou menos importantes na vida e no contexto familiar.

A entrada no "ninho vazio pode ser uma oportunidade para desenvolver novos interesses e ambições, incentivando a satisfação individual e a felicidade do casal.

A abordagem familiar, nestes casos, deverá ser individualizada, atendendo ao carácter dinâmico de uma família e aos fatores de influência como os socioeconómicos.

\section{Resumo}

Os ciclos de vida familiar respeitam uma sequência previsível de transformações na organização familiar em função de tarefas bem definidas. Evelyn Duvall apresentou a primeira classificação do ciclo vital, contemplando oito estádios, considerando a presença de filhos e a idade e evolução do mais velho como critérios adequados para a sua delimitação. Trata-se de um método dinâmico de observação do desenvolvimento da família, que permite contextualizar a situação, aumentar a capacidade de diagnóstico e especialmente antecipar dificuldades. A transição ao longo dos estádios ocorre frequentemente sob momentos de crises, que causam ajustamentos e adaptações. No estádio VII de Duvall as transformações familiares são particularmente intensas e significativas para todos os elementos. Corresponde ao momento em que o último filho sai de casa, deixando os pais para trás e portanto, o "ninho vazio". Esta separação é frequentemente experienciada pelo casal com uma sensação de perda, tristeza ou mesmo depressão. Porém, não se esgota nos aspetos negativos: é também uma oportunidade para desenvolver novos interesses e ambições, incentivando a satisfação individual e a felicidade do casal. A abordagem familiar deverá ser individualizada, atendendo ao carácter dinâmico de uma família e aos fatores de influência como os socioeconómicos. Na verdade, as recentes transformações sociais são merecedoras de uma breve reflexão, uma vez que poderão criar constrangimentos nos habituais eventos do ciclo de vida familiar. O Médico de Família poderá preparar antecipadamente as situações de crise familiar, prevenindo problemas clínicos ou psicossociais.

\begin{abstract}
The family life cycles respect a predictable sequence of transformations in family due to well-defined tasks. Evelyn Duvall presented the first classification of the family life cycle, comprising eight stages, considering the presence of children and the age and evolution of the oldest as appropriate criteria for their delineation. It is a dynamic method for observing the development of the family, which allows contextualize the situation, increase the diagnostic capability and especially to anticipate difficulties. The transition through the stages occurs often in moments of crisis, causing adjustments and adaptations. In Duvall's VII stage the family transformations are particularly intense and significant for all elements. Corresponds to the moment when the last child leaves home, leaving the parents left behind and therefore the "empty nest." This separation is often experienced by the couple with a sense of loss, sadness or even depression. But there's not only negative aspects: it is also an opportunity to develop new interests and ambitions, encouraging individual satisfaction and happiness of the couple. However, the family approach should be individualized, taking into account the dynamic nature of a family and the influencing factors such as socio-economic. In fact, recent social transformations are worthy of a brief reflection, as they may create constraints in usual events of family life cycles. The Family Doctor can prepare in advance the situations of family crisis, preventing clinical or psychosocial problems.
\end{abstract}

Key-words: Family Life Cycles, Primary Care Physician, Primary Health Care. 
Palavras-chave: Síndrome do ninho vazio; Ciclo de vida familiar, Médico de Família, Cuidados de Saúde Primários.

“No estádio VII de Duvall as transformações familiares são particularmente intensas e significativas para todos os elementos. Atendendo ao carácter dinâmico de uma família e aos fatores de influência, as recentes transformações sociais são merecedoras de uma breve reflexão."

\section{Ninhos Vazios e Pássaros Desnorteados}

Não são raras as vezes que ouvimos dos "nossos" doentes os seus desabafos, as suas preocupações e receios. Umas vezes relacionadas com familiares, como os filhos, e outras com eles próprios. São particularidades da Medicina Geral e Familiar (MGF). Não raras vezes contemplamos com eles o presente e procuramos amparar o futuro. Vivemos com eles o que eles vivem. E após a despedida, na inércia do final da consulta, frequentemente damos início a uma auto-reflexão pessoal da nossa própria história. Esta "viagem" é na maioria das vezes involuntária, mas importante para a descontaminação emocional entre consultas, assim como refere Vítor Ramos. ${ }^{1}$

M. está a sofrer por ver sair de casa o seu filho mais novo - é o último de dois filhos a abandonar o lar. Receia a solidão, entristece-se, está insegura com o facto de ter entrado recentemente para a reforma, não ter uma ocupação e sentir-se inútil, sem filhos para cuidar ao fim de tantos anos... Apoquenta-se com o futuro, temendo este momento ser o início de uma espiral de força centrípeta até ao final da vida.

Eu estou "do outro lado" e tenho bem a idade para ser seu filho... Antes de chamar o próximo utente por breves instantes coloco-me no lugar de M. Estou certo que não só aprendemos com as nossas experiências mas também com as dos outros, com quem nos relacionamos. Procuro perceber o que M. estará totalmente a sentir e volto a mim: como estarão os meus pais? Saí de casa há dois anos, sou feliz com a mulher que amo, mas... e eles? Como estarão realmente a adaptar-se a esta fase de grande mudança?

As inquietudes de M. identificam na perfeição um dos estádios contemplados no ciclo de vida familiar. Evelyn Duvall dedicou-se a estudar estes diferentes estádios, tendo nos anos 50 apresentado a primeira classificação do ciclo vital, que hoje é usada como instrumento de avaliação familiar. ${ }^{2,3}$ Contempla oito estádios considerando a presença de filhos e a idade e evolução do mais velho como critérios adequados para a sua delimitação. ${ }^{2}$ É um método dinâmico de observação do desenvolvimento da família, que permite contextualizar a situação, aumentar a capacidade de diagnóstico e especialmente antecipar dificuldades. ${ }^{3} 0$ primeiro estádio diz respeito a uma família sem filhos e o último a uma família idosa (da reforma à viuvez). Pelo meio está uma família que se vai expandir com a chegada do primeiro filho, estabilizar com o período de educação dos filhos até que o primeiro saia de casa e contrair, com o período de saída de casa dos filhos até ao reencontro do casal sem filhos. ${ }^{4}$ No fundo este ciclo respeita uma sequência previsivel de transformações na organização familiar em função de tarefas bem definidas. Essas tarefas correlacionam-se com as características individuais e com a pressão social para o desempenho adequado de tarefas essenciais à continuidade do sistema/família. ${ }^{4}$ Duvall descreveu que a transição ao longo dos estádios ocorria sob momentos de intenso "stress" ou crises, que causavam ajustamentos ou adaptações (positivas ou negativas). ${ }^{2}$ O normal desenvolvimento ao longo dos estádios era assim frequentemente envolto em incertezas, dúvidas sobre as capacidades para enfrentar novas situações e talvez alguma resistência em abandonar o conforto e estabilidade do estádio anterior. ${ }^{5}$

Será sensato refletir e observar que as famílias não transitam de uma fase para outra de forma limpa e estanque. Poderá existir uma sobreposição de estádios ou a família bloquear em certo estádio, dando origem a "sintomas". ${ }^{5}$ Assim, a abordagem familiar deverá também ser individualizada, atendendo ao carácter dinâmico de uma família, fatores de influência como os socioeconómicos e cada vez mais frequentes possibilidades de constituição e organização.

No estádio VII de Duvall as transformações familiares são particularmente intensas e significativas. Corresponde ao momento em que o último filho sai de casa, deixando os pais para trás e portanto, o "ninho vazio". M. é casada e descreve a relação actual com o marido como "amigável". Porém conta que vão longe os tempo de paixão entre o casal, durante os quais os dois "chegavam" para serem felizes. No estádio do ninho vazio, o casal livre das tarefas parentais encontra-se de novo a sós, tal como no princípio do seu relacionamento, mas provavelmente não da mesma forma... Decorreu um longo período das suas vidas (20-30 anos?) e "quase se esqueceram" da sua relação a dois. Os filhos muitas ve- 
zes funcionaram como elos de comunicação, que agora deixaram de existir. 0 casal viveu intensos eventos nas relações familiares, que contribuíram para a individualização dos elementos, sendo quase inevitável a invasão num primeiro momento de um sentimento de perda, tal como sente a "nossa" M. Do casal, é habitualmente a mulher quem vive esta separação com especial tristeza, depressão ou mesmo hostilidade. Ocasionalmente poderão estar presentes comportamentos conscientes ou não de manipulação que por exemplo, poderão condicionar a saída do último filho e manifestar-se através de sintomas psicossomáticos, como a ansiedade. ${ }^{5}$

Possivelmente, o casal é de súbito confrontado com uma assídua presença dos seus eus autobiográficos: ${ }^{6}$ uma autobiografia mental e consciente, intimamente relacionada com a identidade e os sentimentos. Na esperança média de vida actual, pelo menos metade das suas vidas já passou... é uma altura propícia para questionar se os sonhos e projetos foram alcançados. E no futuro, ponderar sobre os valores e prioridades na vida. M., parece-me, encontra-se nesta fase de contemplação, de deriva e mesmo alienação. Desejo no futuro poder ajudá-la no delinear de novos interesses ou actividades.

De facto, o ninho vazio não se esgota nos aspetos negativos. Como transição natural há que contemplar os benefícios para todos. O casal fica perante a oportunidade de desenvolver novos interesses e ambições, incentivando a satisfação individual e a felicidade do casal. Com a saída dos filhos, ficam igualmente desafogados em termos financeiros e possivelmente menos expostos a exigências profissionais com o início da reforma. Assim, frequentemente coexistem sentimentos ambivalentes de libertação e satisfação marital em oposição a outros de vazio, perda e de luto. ${ }^{5}$

Tanto para o casal como para os filhos, é um momento de desafio, de novidade, de aprendizagem e conquista. Os pais procurando restabelecer o seu relacionamento e os filhos procurando construir a sua autonomia. Quando os filhos saem constituindo novas famílias, o processo poderá ser mais complexo, com o entrecruzamento de novas histórias familiares. Todo o contexto familiar se refaz com novas adaptações e flexibilizando relacionamentos. ${ }^{5}$

Uma pequena ressalva vai para o facto que a maioria dos modelos do ciclo de vida familiar, dizem respeito a uma familiar nuclear "típica" (com filhos), que têm vindo a diminuir ao longo dos anos. ${ }^{7}$ Por sua vez, são cada mais frequentes os divórcios, as pessoas sós, as famílias homossexuais, reconstituídas, monoparentais ou os casais sem filhos, nas quais estas classificações não se adaptam. ${ }^{7}$
Perante as recentes transformações sociais (difíceis de ignorar), uma breve reflexão depara com múltiplos constrangimentos nesta fase do ciclo de vida familiar. Constrangimentos esses, que fazem do ninho vazio de M. um ninho cada vez menos frequente... Atualmente muitos dos filhos que atingem a idade ótima para "voar" parece não o fazerem, adiando essa investida. ${ }^{8}$ Em Portugal, mais de $15 \%$ dos jovens com idades entre os 30 e os 34 anos ainda reside com a família de origem. ${ }^{8}$ Os motivos porque isto acontece serão variados: taxa de desemprego jovem muito elevada (42.1\% no $1^{\circ}$ trimestre de 2013 em Portugal), condições precárias de trabalho, dificuldades económicas e de acesso a créditos bancários, expectativas demasiado elevadas após terem sido criados num ambiente económico "confortável" e debaixo das asas parentais (gerações "Y" e "Peter Pan”), etc.

Que perigos poderão advir de um "voo" tardio? Há certamente alturas mais próprias para errar e essa poderá ser uma exigência das sociedades, como habituais criadoras de estereótipos. Por opção mais ou menos imposta (exigências sociais/laborais e contrações económicas), hoje em dia o estado civil solteiro e sem filhos tende a aumentar e alongar-se, formando-se menos famílias "típicas" e mais tardiamente. ${ }^{7}$ Por sua vez, os pais poderão nunca experienciar a função de avós. Isso será de lamentar uma vez que a chegada dos netos muitas vezes “apazigua” esta fase de vida, atribuindo aos avós uma função familiar válida e contribuem para o sentido de continuidade, utilidade e pertença do sistema familiar, providenciando um reforço nos elos familiares. Outro fenómeno actual observado, são as situações em que os filhos abandonam o lar para estudar ou para trabalhar e mais tarde regressam (forçados ou não), por vezes até já acompanhados de uma nova família...

Com filhotes graúdos, o ninho fica assim mais pequeno para todos ou mesmo sobrelotado, quando "deveria" por essa altura estar "vazio". Que problemas isso trará? Mesmo podendo encontrarem-se livres das tarefas parentais, os casais ficam privados de novos papéis sociais, da renovação de interesses, participação de atividades e de se reencontrarem e aumentarem a sua satisfação conjugal, inclusive em termos do relacionamento sexual. ${ }^{5}$ Outra austeridade imposta são os cortes nas suas reformas, que associada à necessidade de sustentar os filhos até cada vez mais tarde, afastam o desafogo financeiro habitual desta fase. Adicionalmente, com o aumento da esperança média de vida e da idade da reforma, trabalham também até mais tarde. O ninho vazio poderá assim ser ameaçado ou ocorrer mais tarde num momento em que coincide com eventos cumulativos: início da reforma, início de doenças crónicas, menopausa nas mulheres, etc, o que pode ampli- 
ficar os sentimentos de perda e a exigência de ajustes e adaptações. Da geração anterior, os próprios pais do casal encontrar-se-ão mais velhos e dependentes, necessitando possivelmente nesta fase de cuidados. Este ponto é igualmente importante de refletir, atendendo que com o aumento da emigração e a formação de menos famílias com menos descendentes, poder-se-ão criar fragilidades nas redes de suporte social.

\section{O Médico de Família e os "ninhos vazios"}

O Médico de Família (MF) tem um lugar privilegiado ao longo das diversas fases do ciclo familiar que lhe permitirá prevenir alguns problemas clínicos, psicossociais e na prestação de ajuda nas situações de crises. A utilização de instrumentos de classificação do ciclo de vida familiar fornece um valioso contributo ao centrar-se na evolução temporal das interações familiares, permitindo o diagnóstico e o planeamento da intervenção. ${ }^{4}$ Há crises esperadas e portanto pontos-chave de intervenção do MF. No ninho vazio, prevenir passa por preparar antecipadamente a partida dos filhos, ajudando a família a descobrir e a dedicar-se a novos interesses exteriores, a novas aptidões e capacidades. ${ }^{5}$ É importante que cada elemento realize

\section{Referências Bibliográficas}

1. Ramos V. A consulta em 7 passos. Execução e análise crítica de consultas em Medicina Geral e Familiar. Revista Portuguesa de Medicina Geral e Familiar. 2009;25:208-20. [Citado a 27 de Agosto de 2013]. Disponivel em: http:// www.rpmgf.pt/ojs/index.php?journal=rpmgf\&page $=$ article \&op=view\&path\%5B\%5D=10609

2. Duvall EM. Marriage and family development. 5th ed. Philadelphia: Lippincott; 1977.

3. Laginha T, Marau J. Grupo de Saúde Familiar da APMCG. Instrumentos de Apoio à Prática Clinica em Cuidados de Saúde Primários. Ciclo de Vida da Família (adaptado de Duvall),

4. Ribeiro C. MGF2000, Parte II - Promoção e proteção da saúde nas diferentes fases de vida. Pessoa, família, saúde e doença. Ciclos vitais. [Citado a 27 de Agosto de

\section{Conflito de Interesses}

O autor declara não ter conflito de interesses para este artigo.

\section{Endereço para Correspondência:}

Vítor Bruno Portela Lopes Cardoso

Rua João Gomes Leite n. ${ }^{\circ}$ 37, Real. 4700-276 Braga

Telemóvel: 937650671

Email: muxmail@gmail.com novos investimentos quer em si mesmo, quer na relação mútua, podendo o MF enfatizar a importância da comunicação e suporte recíproco. 0 ideal será provavelmente iniciar todo este processo com os filhos ainda em casa para que assim fiquem aptos de forma suave a enfrentar este período. ${ }^{5}$ O MF deverá pois estar sensibilizado para este estádio da vida familiar, nomeadamente para os problemas de saúde que lhe estão associados. Os sentimentos de tristeza e a ansiedade, por exemplo, são formas frequentes de apresentação no ninho vazio. No encontro à definição da MGF, este poderá ser um exemplo em que como o MF vai para além da organicidade do seu doente, abordando-o como um todo que está naturalmente inserido numa família e num contexto social.

Nota: M. é uma personagem ficcional que integra a identidade de situações e utentes vivenciados pelo autor.

\section{Agradecimentos}

O autor gostaria de agradecer à Dra. Paula Mendes e à Dra. Cláudia Melo, pela revisão crítica do artigo.

2013]. Disponivel em: http://csgois.web.interacesso.pt/ MGFV001MASTER/textos/21/26_texto.html

5. Brito da Luz LJ, Brito da Luz JP. MGF2000, Parte III - Saúde e ambientes. Ambiente familiar. A síndroma do "ninho vazio". [Citado a 27 de Agosto de 2013]. Disponível em: http://csgois.web.interacesso.pt/MGFV001MASTER/ textos/31/109_texto.html

6. Damásio A. O Livro da Consciência. A construção do cérebro consciente. Portugal: Círculo de Leitores e Temas e Debates, 2010.

7. Censos 2011: XV recenseamento geral da população: V recenseamento geral da habitação: resultados definitivos/ Instituto Nacional de Estatística. - Lisboa, Portugal. [Citado a 27 de Agosto de 2013]. Disponível em: http://censos. ine.pt

8. Rebelo R. A família em Medicina Geral e Familiar. Conceitos e Práticas. Lisboa: Verlag Dashofer, 2011. 